\title{
Anesthesia management in a patient with Carney Syndrome: Case report
}

\author{
Abdullah Kahraman ${ }^{*}$ and Cahide Kahraman \\ Department of Anestesiology, Van State Education and Research Hospital, Health Science University, Ministry of \\ Health, Van, Turkey
}

\begin{abstract}
Carney Syndrome is a complex of symptoms which can demonstrate autosomal dominant or sporadic transition that are followed by cardiac and cutaneous myxomas and endocrine abnormal activity. Myxomas demonstrate familial transition due to autosomal dominant inheritance at a rate approximately of $5 \%$. In anesthesia management, some of the significant things to be paid attention to are; the localization, size and mobility of the myxoma. Rate of familial myxoma after surgical resection is about 21-67\%. In this article, anesthesia practice in a Carney Syndrome case with cerebral aneurysms that is scheduled for operation due to surrenalectomy, has been presented.
\end{abstract}

Key Words: Anesthesia management, Carney Syndrome, cerebral aneurysm

\section{Introduction}

Carney Syndrome is a complex of symptoms which can demonstrate autosomal dominant or sporadic transition that are followed by cardiac and cutaneous myxomas and endocrine abnormal activity. Myxomas demonstrate familial transition due to autosomal dominant inheritance at a rate approximately of $5 \% .80 \%$ of non-familial sporadic myxoma has normal DNA structure, whereas $20 \%$ has abnormal chromosomal structure. Familial myxomas, unlike sporadic myxomas are encountered in younger patients as equally in both sexes (1).

Although myxomas are $70 \%-80 \%$ benign, they can lead to complications such as; cyst and microabscess formation, embolization, syncope and sudden death. Cardiac myxomas can rarely collocate with primary nodular adrenal cortical disease and pituitary adenomas (2,3). In this article, anesthesia practice in a Carney Syndrome case with cerebral aneurysms that is scheduled for operation due to surrenalectomy, has been presented.

\section{Case report}

Nineteen-year-old female patient with Carney Syndrome for whom surrenalectomy had been scheduled was assessed in the anesthesiology polyclinic. Patient history informed that the patient had been operated 6 years ago due to left atrial myxoma, 4 years ago myxoma had recurred, and the patient had cerebral infarct secondary to myxoma and loss of sight in the left eye. Aneurysm in the left bifurcation of MCA (Middle Cerebral Artery) was detected in MR angiography of the patient. As a result of endocrine consultation, implementation of perioperative steroid umbrella was recommended due to Cushing syndrome.

The patient's general condition was fine, she was conscious and had no motor or sensory deficits. In preoperative evaluation, she was reported as $46 \mathrm{~kg}$ and ASA 3. Preoperatively ECG (electrocardiogram) SpO2 (97\%), arterial blood pressure $(128 / 68 \mathrm{mmHg})$ and heart rate $(84 \mathrm{BPM})$ were monitored. After $2 \mathrm{mg}$ midazolam IV was implemented to the patient with premedication purposes, $2 \mathrm{mcg} / \mathrm{kg}$ fentanyl, $2 \mathrm{mg} / \mathrm{kg}$ propofol and $0.1 \mathrm{mg} / \mathrm{kg}$ vecuronium were implemented for induction of general anesthesia. After the induction, the patient was intubated with 6.5 numbered endotracheal tube. Maintenance of anesthesia was proceeded with $50 \%(2 \mathrm{l} / \mathrm{min})$ and $50 \%$ dry air $(21 / \mathrm{min})$ mixture of $2 \%$ sevoflurane. Perioperative prednol $20 \mathrm{mg}$ IV was implemented 4 times. Non-occurrence of perioperative hypoxia and hypo-hypertension attacks in the patient was 
paid attention to. No intraoperative problems came up. Postoperative muscle relaxant effect was reversed with atropine $(0.01 \mathrm{mg} / \mathrm{kg})$ and neostigmine $(0.03 \mathrm{mg} / \mathrm{kg})$ and the patient was sent to the service without any problems.

\section{Discussion}

In the complex expressed as Carney Syndrome, there are atypical localized myxomas (heart, skin, mucosal tissue) and skin pigmentation. Infrequently, hyperactivity symptoms of endocrine organs, gigantism and pituitary adenomas followed by acromegaly, fibro adenomas testicles tumors $(4,5)$. Because of the risk of sudden death and embolization, noninvasive methods are preferred in the diagnosis. The diagnosis is made in almost all of the patients via echocardiography (6). The reported recurrence rate of familial myxomas after surgical resection is about $21-67 \%$ (5).

In anesthesia management, some of the significant things to be paid attention to are; the localization, size and mobility of the myxoma.

The most common findings related to endocrine organs are Cushing's syndrome due to ACTH production, acromegaly, thyroid and testicular tumors. Tumoral formations within the syndrome require different treatments depending on the localization, magnitude, the clinical situation of the secreted hormones (3). Indeed, the case we have been presenting has undergone surgery due to Cushing's syndrome.

Left atrial microsoma can lead to pulmonary hypertension symptoms by causing obstruction in mitral or pulmonary vein. They can cause complications such as embolization, infection, syncope and sudden death $(4,7)$. In our case, as well the patient had cerebral infarction before and had loss of sight in her left eye.

As a result, it must be remembered that, cases with Carney Syndrome can come in front of the anesthesiologist due to cardiac myxoma, and endocrine diseases or their complications. In these cases, nonoccurrence of perioperative hypoxia and hypo-hypertension attacks in the patient must be paid attention to.

\section{References}

1. Hall RA, Anderson RP. Cardiac neoplasms. In: Edmunds LH Jr, editor. Cardiac surgery in the adult. New York: McGraw-Hill; 1997, pp 13451362.

2. Diniz G, Temir G, Ortaç R. Angiomyxoma: Always mixoid, sometimes agressive. Turkish Journal of Pathology 2012; 28: 162-164.

3. Gür AK, Kaya Y, Karakurt A, Güvenç TS. The Carney syndrome associated fibroelastoma and myxoma. Dicle Medical Journal 2012; 39: 413 415.

4. Mete A, Sancaktar O, Süleymanlar G, et al. Carney's Syndrome in association with left atrial myxoma. GKD Cer Derg 1995; 3: 270-272.

5. Kapısız NS, Kapısız HF, Doğan OV, Yucel E. Recurrent familial cardiac myxomas in a mother and daughter with Carney's syndrome. Turkish J Thorac Cardiovasc Surg 2009; 17: 40-42.

6. Uygur F, Erdoğan M, Meşe B, et al. Cardiac myxoma: Five years surgical experience Turkish J Thorac Cardiovasc Surg 2005; 13: 120-122.

7. Stevens LH, Hormuth DA, Schmidt PE, Atkins S, Fehrenbacher JW. Left atrial myxoma: pulmonary infarction caused by pulmonary venous occlusion. Ann Thorac Surg 1987; 43: 215-217. 